\title{
Feasibility and Effectiveness of Using Wearable Activity Trackers in Youth: A Systematic Review
}

Nicola D Ridgers ${ }^{1}$, BSc (Hons), MSc, PhD; Melitta A McNarry ${ }^{2}$, BSc (Hons), PhD; Kelly A Mackintosh ${ }^{2}$, BSc (Hons), $\mathrm{MSc}, \mathrm{PhD}$

${ }_{1}^{1}$ Deakin University, Geelong, Australia, Institute for Physical Activity and Nutrition (IPAN), School of Exercise and Nutrition Sciences

${ }^{2}$ Applied Sports Science Technology and Medicine Research Centre (A-STEM), College of Engineering, Swansea University, Swansea, United Kingdom

\section{Corresponding Author:}

Nicola D Ridgers, BSc (Hons), MSc, PhD

Institute for Physical Activity and Nutrition (IPAN)

School of Exercise and Nutrition Sciences

Deakin University

221 Burwood Highway

Burwood, 3125

Australia

Phone: 610392446718

Fax: 610392446017

Email: nicky.ridgers@deakin.edu.au

\section{Abstract}

Background: The proliferation and popularity of wearable activity trackers (eg, Fitbit, Jawbone, Misfit) may present an opportunity to integrate such technology into physical activity interventions. While several systematic reviews have reported intervention effects of using wearable activity trackers on adults' physical activity levels, none to date have focused specifically on children and adolescents.

Objective: The aim of this review was to examine the effectiveness of wearable activity trackers as a tool for increasing children's and adolescents' physical activity levels. We also examined the feasibility of using such technology in younger populations (age range 5-19 years).

Methods: We conducted a systematic search of 5 electronic databases, reference lists, and personal archives to identify articles published up until August 2016 that met the inclusion criteria. Articles were included if they (1) specifically examined the use of a wearable device within an intervention or a feasibility study; (2) included participants aged 5-19 years old; (3) had a measure of physical activity as an outcome variable for intervention studies; (4) reported process data concerning the feasibility of the device in feasibility studies; and (5) were published in English. Data were analyzed in August 2016.

Results: In total, we identified and analyzed 5 studies ( 3 intervention, 2 feasibility). Intervention delivery ranged from 19 days to 3 months, with only 1 study using a randomized controlled trial design. Wearable activity trackers were typically combined with other intervention approaches such as goal setting and researcher feedback. While intervention effects were generally positive, the reported differences were largely nonsignificant. The feasibility studies indicated that monitor comfort and design and feedback features were important factors to children and adolescents.

Conclusions: There is a paucity of research concerning the effectiveness and feasibility of wearable activity trackers as a tool for increasing children's and adolescents' physical activity levels. While there are some preliminary data to suggest these devices may have the potential to increase activity levels through self-monitoring and goal setting in the short term, more research is needed to establish longer-term effects on behavior.

(JMIR Mhealth Uhealth 2016;4(4):e129) doi: 10.2196/mhealth.6540

\section{KEYWORDS}

behaviour change; electronic activity monitor; mHealth; physical activity 


\section{Introduction}

Physical inactivity is a global pandemic and has been identified as the fourth leading cause of death worldwide [1]. Regular physical activity plays a critical role in preventing precursors to metabolic and cardiovascular ill health in children [2], providing numerous health benefits during childhood that persist into adulthood [3]. Such health benefits include protective effects on bone health, as well as positive effects on fitness, body fat, and blood pressure [4]. Several countries (eg, the United States, United Kingdom, and Australia) recommend that children should engage in at least 60 minutes of moderate- to vigorous-intensity physical activity (MVPA) every day to benefit health [5-7]. However, the majority of children and adolescents (defined as youth hereinafter) do not meet these recommended levels and are therefore not sufficiently active to accrue the associated health benefits [8-10]. Since physical inactivity is a major, yet modifiable, risk factor for the burden of disease, there is a need for effective, preventive interventions that aim to increase physical activity levels in this population.

Self-monitoring has been identified as an effective behavior change technique that has been used in behavioral interventions targeting increases in physical activity levels [11]. Indeed, self-monitoring and feedback are fundamental to increasing awareness of individual physical activity levels, which is particularly important given that youth are unlikely to change their behavior if they do not know how active they actually are and how this translates to government guidelines. Specifically, Corder and colleagues found that approximately $60 \%$ of inactive adolescents thought that they met physical activity guidelines [12], suggesting that they may see no need to change their behavior, despite the associated health benefits. Traditionally, hip-worn pedometers have been used to increase individuals' awareness of their physical activity [13]; however, participants are required to record their activity at the end of each day, which can be burdensome for them [13]. In recent years, there has been increasing interest in emerging technologies and wearable sensors as self-monitoring tools for promoting physical activity levels [14]. The proliferation of wearable activity trackers, as well as their growing commercial availability, popularity, and widespread adoption [15], presents an opportunity to integrate such technologies into physical activity interventions. While ownership data are not available for youth, it is estimated that $10 \%$ and $20 \%$ of US and Australian adults, respectively, own some form of wearable technology $[15,16]$. An integral component of wearable activity trackers, such as Fitbit and Jawbone, is the automation of real-time physical activity tracking [17]. The wireless syncing of such devices to Web- or app-based profiles not only negates the burden of manual data entry, but also enables the wearer to self-monitor against physical activity recommendations or set goals [14,17].

To date, physical activity research has primarily focused on establishing the validity and reliability of wearable activity trackers for measuring a range of outcomes, including steps and sleep [18]. In comparison, little is known about the feasibility and effectiveness of these devices as a tool for increasing physical activity levels, whether in isolation or in combination with other strategies. A recent review reported that there was some initial evidence that wearable activity trackers can increase physical activity levels, though only studies conducted in adult populations were included [19]. Given that engagement with technology is a highly valued behavior for youth and plays an important role in different domains of their lives (eg, education, socialization, and entertainment; [20]), there is a need to establish whether wearable activity trackers are feasible and effective in changing physical activity levels in this population. Such information is important for informing future physical activity interventions and has the potential to contribute to the development of public health guidance concerning the role of these tools in physical activity and health promotion practice.

The aim of this review, therefore, was to examine the effectiveness of wearable activity trackers as a tool for increasing children's and adolescents' physical activity levels. We also examined the feasibility of using such technology in youth populations (defined as those in the age range 5-19 years).

\section{Methods}

We conducted a systematic literature search in accordance with the Preferred Reporting Items for Systematic Reviews and Meta-Analyses (PRISMA) statement [21]. We searched 5 electronic databases (PubMed, Web of Science, SPORTDiscus, Scopus, and ProQuest Central). Search strategies for the different databases included the following search strings in four main areas: wearable activity trackers (electronic track*, electronic activ*, electronic monitor, electronic fitness track*, wearable device, wearable act*, wearable track*, consumer wearable, Fitbit, SenseWear, Jawbone, Nike Fuelband, PAM), population (child*, adolescent, youth), study design (intervention, trial, feasibility), and outcome variable (physical activity, energy expenditure, fitness, exercise). The full search strategies for each database are presented in Multimedia Appendix 1. Articles that had been published in peer-reviewed journals or conference proceedings were considered for review. We did not include abstracts, dissertations, systematic reviews, and case studies. In addition to electronic searches, we also searched our personal collections and the bibliographies of retrieved studies. This is a commonly used approach for the identification of additional relevant studies for potential inclusion in systematic reviews [22].

For the purpose of this review, we defined wearable activity trackers as an electronic device with the following features: was designed to be worn on the user's body; uses accelerometers, altimeters, or other sensors to track the wearer's movements or biometric data, or both; and can provide feedback, beyond the display of basic activity count information, via the monitor display or through a partnering app to elicit continual self-monitoring of activity behavior $[19,23]$. To be included in the review, studies were required to (1) specifically examine the use of a wearable device within an intervention or a feasibility study; (2) include participants aged 5-19 years old; (3) have a measure of physical activity as an outcome variable for intervention studies; (4) report process data concerning the feasibility of the device in feasibility studies; (5) be published between the start date of each electronic database and August 2016; and (6) be published in English. We excluded studies that 
reported study protocols, used mobile phones rather than a wearable activity tracker, used mobile phone or tablet apps without an accompanying wearable activity tracker, or only used the wearable activity tracker to evaluate an intervention (eg, worn at baseline and postintervention). In the event that a wearable activity tracker was used in conjunction with other tools, such as Facebook to share activity tips, studies were eligible for inclusion if physical activity data were reported or the feasibility of the device was reported separately. Studies that implemented the use of such technologies in clinical populations were eligible for inclusion if the focus was on using a wearable device to increase physical activity levels. When studies were still in press or were an advanced publication ahead of print but had a unique digital object identifier, they were eligible for inclusion. Conference proceedings were eligible for review due to the potential for such devices to be examined in different disciplines (eg, computer science) where such outputs are often more reputable than journal articles.

All authors independently assessed the results obtained from the initial literature search. Articles were screened in 4 steps: first, we removed duplicates, then screened the title, abstract, and full text. We then screened the articles based on the inclusion and exclusion criteria outlined above. If we could not determine suitability during the screening of the title and abstract, we accessed full-text articles and compared them against the inclusion criteria. Any disagreements were settled by discussion between the authors. We then extracted the following data using a standardized form for each study that met the inclusion criteria: country of study, study design, sample characteristics (eg, sample size, age), wearable device used, and results. The first author extracted the data, which were checked by the remaining authors (MAM, KAM). We then undertook a narrative review of the included studies.

The second and last authors (MAM, KAM) independently assessed the risk of bias in the intervention studies that met the inclusion criteria. We adapted the criteria for assessing risk of bias from the Methods Guide for Comparative Effectiveness Reviews [24] and previous reviews in similar areas [19]. We identified 8 criteria as being important to this review: (1) participants were allocated randomly; (2) an adequate proportion of participants had complete data for the outcome variable (ie, no more than $20 \%$ of data were missing); (3) data were analyzed according to group allocated; (4) the study population was representative of the population of interest; (5) the timing of outcome assessments was similar in all groups; (6) the study reported the validity of the device used (either data were provided in the article or there was an appropriate reference to the original study); (7) the study reported the reliability of the device used (either data were provided in the article or there was an appropriate reference to the original study); and (8) the study was conducted independently of the manufacturer of the device used. We assessed only the last 3 risk-of-bias criteria for feasibility studies given the nature of such study designs. Each criterion was scored as "yes" (1), "no" (0), or "unsure" (?).

\section{Results}

We screened and analyzed data in August 2016. Through the systematic search, we initially identified 259 articles, then identified 1 additional article through other sources. Of these, 5 were included in the review (Figure 1): 3 were intervention studies [25-27] and focused primarily on increasing physical activity levels across the whole day [26,27] or during recess [25], and 2 studies were classed as feasibility studies [28,29]. Of the intervention studies, 2 [26,27] also included process measures about the device used. The majority of the studies $(n=4)$ focused on children and were conducted in the United States [25,27-29]. The main brand of wearable device used was Fitbit $[25,27,28]$. Table 1 reports the characteristics of each included study. Figure 2 shows the different wearable devices used in the included studies, and Table 2 provides an overview of the features of these devices.

Table 3 reports the risk of bias for each study. All were conducted independently of the manufacturers of the device(s) used, while 2 studies reported the reliability and validity of the devices used. Of the intervention studies conducted, only 1 used a randomized controlled trial design [26]. 
Table 1. Summary of included studies on the effectiveness and feasibility of wearable activity trackers in youth (chronological order by study design).

\begin{tabular}{|c|c|c|c|c|c|c|}
\hline Study & Country & Participants & $\begin{array}{l}\text { Type of } \\
\text { study }\end{array}$ & Study design and description & Device examined & Outcomes assessed \\
\hline $\begin{array}{l}\text { Slootmaker, } \\
2010[26]\end{array}$ & $\begin{array}{l}\text { Nether- } \\
\text { lands }\end{array}$ & $\begin{array}{l}\text { Adolescents }(13- \\
17 \text { years old), } 32 \\
\text { boys, } 55 \text { girls } \\
\text { (15.1 years) at } \\
\text { baseline }\end{array}$ & $\begin{array}{l}\text { Intervention } \\
\text { plus feasibili- } \\
\text { ty compo- } \\
\text { nent }\end{array}$ & $\begin{array}{l}\text { Least active group of youth } \\
\text { recruited. Randomized to } \\
\text { intervention or control. 3- } \\
\text { month Web-based interven- } \\
\text { tion combining self-monitor- } \\
\text { ing, goal setting, device and } \\
\text { PAM COACH. }\end{array}$ & $\begin{array}{l}\text { PAM and PAM } \\
\text { COACH }\end{array}$ & 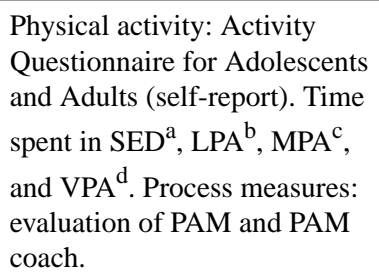 \\
\hline $\begin{array}{l}\text { Hayes, } 2015 \\
{[25]}\end{array}$ & USA & $\begin{array}{l}6 \text { grade- } 3 \text { girls } \\
\text { (aged } 8 \text { years old) } \\
\text { from } 1 \text { school; in- } \\
\text { tact social group }\end{array}$ & Intervention & $\begin{array}{l}\text { Recess intervention ( } 22 \text { ses- } \\
\text { sions in total). Fitbit used to } \\
\text { self-monitor physical activi- } \\
\text { ty levels against set goals. } \\
\text { Tangible rewards provided } \\
\text { if goals met. }\end{array}$ & $\begin{array}{l}\text { Fitbit (model not re- } \\
\text { ported) }\end{array}$ & $\begin{array}{l}\text { Steps/recess. MVPA }{ }^{\mathrm{e}}(\mathrm{min}) \\
\text { during recess. }\end{array}$ \\
\hline $\begin{array}{l}\text { Hooke, } 2016 \\
\text { [27] }\end{array}$ & USA & $\begin{array}{l}16 \text { children ( } 5 \\
\text { boys, } 11 \text { girls) } \\
\text { aged mean } 8.7 \text {, } \\
\text { SD } 3.1 \text { years; } \\
\text { participants re- } \\
\text { ceiving a cycle of } \\
\text { maintenance } \\
\text { chemotherapy for } \\
\text { lymphoblastic } \\
\text { leukemia }\end{array}$ & $\begin{array}{l}\text { Intervention } \\
\text { plus feasibili- } \\
\text { ty compo- } \\
\text { nent }\end{array}$ & $\begin{array}{l}\text { Used for } 17 \text { days before and } \\
5 \text { days after a corticosteroid } \\
\text { pulse. Step goal tailored } \\
\text { based on data and daily } \\
\text { feedback against goal provid- } \\
\text { ed (either to increase or } \\
\text { maintain physical activity). } \\
\text { Goal set in Fitbit website by } \\
\text { study nurse for participants } \\
\text { to track progress. }\end{array}$ & Fitbit One & $\begin{array}{l}\text { Steps/day. Feasibility compo- } \\
\text { nent included ease of recruit- } \\
\text { ment, ease of use and enjoy- } \\
\text { ment of Fitbit, and days of } \\
\text { wear. }\end{array}$ \\
\hline $\begin{array}{l}\text { Schaefer, } \\
2014 \text { [29] }\end{array}$ & USA & $\begin{array}{l}24 \text { children }(11 \\
\text { boys, } 13 \text { girls }) \\
\text { aged } 7-10 \text { years } \\
\text { (mean } 8.9, \text { SD } \\
1.3 \text { years) }\end{array}$ & Feasibility & $\begin{array}{l}\text { Each child wore a different } \\
\text { monitor for } 1 \text { week ( } 4 \text { weeks } \\
\text { total). Underwent structured } \\
\text { interview about each device } \\
\text { and then summary (exit) in- } \\
\text { terview at the end, with } \\
\text { child and parents inter- } \\
\text { viewed separately. }\end{array}$ & $\begin{array}{l}\text { Actical } \\
\text { SenseWear } \\
\text { Polar Active Polar } \\
\text { heart rate monitor }\end{array}$ & $\begin{array}{l}\text { Frequency of removal, reasons } \\
\text { for removal, enjoyment, com- } \\
\text { fort of use, favorite/least fa- } \\
\text { vorite device characteristics. } \\
\text { Devices also ranked in terms of } \\
\text { most and least favorite. }\end{array}$ \\
\hline $\begin{array}{l}\text { Schaefer, } \\
2016[28]\end{array}$ & USA & $\begin{array}{l}34 \text { children }(22 \\
\text { boys, } 12 \text { girls) } \\
11-12 \text { years old } \\
\text { (mean age } 12.6 \\
\text { years); attending } \\
\text { a low-socioeco- } \\
\text { nomic-status } \\
\text { school }\end{array}$ & Feasibility & $\begin{array}{l}\text { 6-month feasibility study. } \\
\text { Initially asked to wear de- } \\
\text { vices during after-school } \\
\text { program, which then in- } \\
\text { creased to daily wear. }\end{array}$ & Fitbit One & $\begin{array}{l}\text { Fitbit data (ie, steps). Inter- } \\
\text { views examining experiences } \\
\text { of using the Fitbit. }\end{array}$ \\
\hline
\end{tabular}

${ }^{\mathrm{a}} \mathrm{SED}$ : sedentary time.

bPA: light-intensity physical activity.

${ }^{c}$ MPA: moderate-intensity physical activity.

${ }^{d}$ VPA: vigorous-intensity physical activity.

${ }^{\mathrm{e}}$ MVPA: moderate- to vigorous-intensity physical activity. 
Table 2. Overview of features of wearable devices used in the included studies on the effectiveness and feasibility of wearable activity trackers in youth.

\begin{tabular}{|c|c|c|c|c|c|c|c|}
\hline Device & $\begin{array}{l}\text { Location } \\
\text { worn }\end{array}$ & Main measures & $\begin{array}{l}\text { Device dis- } \\
\text { play }\end{array}$ & Compatibility & Sensors & Memory & Waterproof \\
\hline Fitbit One & Waist & $\begin{array}{l}\text { Steps, stairs, dis- } \\
\text { tance, calories, sleep }\end{array}$ & Yes & $\begin{array}{l}\text { Personal computer, } \\
\text { iOS, Android, Windows }\end{array}$ & $\begin{array}{l}\text { Accelerometer ( } 3 \text { axis), } \\
\text { altimeter }\end{array}$ & Up to 23 days & No \\
\hline PAM & Waist & $\begin{array}{l}\text { Physical activity } \\
\text { score }\end{array}$ & Yes & Personal computer & Accelerometer ( 3 axis) & Not reported & No \\
\hline SenseWear & $\begin{array}{l}\text { Upper } \\
\text { arm }\end{array}$ & $\begin{array}{l}\text { Physical activity, } \\
\text { energy expenditure, } \\
\text { steps, sleep }\end{array}$ & $\begin{array}{l}\text { No (option- } \\
\text { al display } \\
\text { required) }\end{array}$ & Personal computer & $\begin{array}{l}\text { Accelerometer ( } 3 \text { axis), } \\
\text { heat flux, galvanic skin } \\
\text { response, skin tempera- } \\
\text { ture, near-body ambient } \\
\text { temperature }\end{array}$ & Up to 34 days & No \\
\hline Actical & $\begin{array}{l}\text { Wrist, } \\
\text { waist, an- } \\
\text { kle }\end{array}$ & $\begin{array}{l}\text { Physical activity, } \\
\text { energy expenditure, } \\
\text { steps }\end{array}$ & No & Personal computer & $\begin{array}{l}\text { Accelerometer (omnidi- } \\
\text { rectional) }\end{array}$ & Up to 194 days & Yes \\
\hline Polar Active & Wrist & $\begin{array}{l}\text { Physical activity, } \\
\text { steps, calories, sleep }\end{array}$ & Yes & $\begin{array}{l}\text { Personal computer, } \\
\text { iOS, Android }\end{array}$ & Accelerometer ( 3 axis) & $\begin{array}{l}21 \text { days (activity } \\
\text { diary) }\end{array}$ & Yes \\
\hline $\begin{array}{l}\text { Polar heart } \\
\text { rate monitor }\end{array}$ & Chest & Heart rate, calories & No & Personal computer & Heart rate & Up to 30 hours & Yes \\
\hline
\end{tabular}

Table 3. Risk-of-bias results ${ }^{\mathrm{a}}$ in studies on the effectiveness and feasibility of wearable activity trackers in youth.

\begin{tabular}{|c|c|c|c|c|c|c|c|c|}
\hline Study & $\begin{array}{l}\text { Random allo- } \\
\text { cation }\end{array}$ & $\begin{array}{l}\text { Minimal } \\
\text { missing data }\end{array}$ & $\begin{array}{l}\text { Analyzed in } \\
\text { group allocat- } \\
\text { ed }\end{array}$ & $\begin{array}{l}\text { Representative } \\
\text { sampling }\end{array}$ & $\begin{array}{l}\text { Timing of out- } \\
\text { come assess- } \\
\text { ments }\end{array}$ & $\begin{array}{l}\text { Reliability of } \\
\text { device }\end{array}$ & $\begin{array}{l}\text { Validity of } \\
\text { device }\end{array}$ & $\begin{array}{l}\text { Independence } \\
\text { from device man- } \\
\text { ufacturer }\end{array}$ \\
\hline $\begin{array}{l}\text { Hayes, } 2015 \\
{[25]}\end{array}$ & 0 & 0 & 1 & 0 & 1 & 1 & 1 & 1 \\
\hline $\begin{array}{l}\text { Hooke, } 2016 \\
\text { [27] }\end{array}$ & 0 & 1 & 1 & 0 & 1 & 1 & 1 & 1 \\
\hline $\begin{array}{l}\text { Schaefer, } \\
2014 \text { [29] }\end{array}$ & $\mathrm{N} / \mathrm{A}^{\mathrm{b}}$ & N/A & N/A & N/A & N/A & 0 & 0 & 1 \\
\hline $\begin{array}{l}\text { Schaefer, } \\
2016 \text { [28] }\end{array}$ & N/A & N/A & N/A & N/A & N/A & 0 & 0 & 1 \\
\hline $\begin{array}{l}\text { Slootmaker, } \\
2010 \text { [26] }\end{array}$ & 1 & 1 & 1 & 1 & 1 & 0 & 0 & 1 \\
\hline
\end{tabular}

${ }^{\mathrm{a}}$ Scored as follows: $1=$ yes; $0=$ no.

${ }^{\mathrm{b}} \mathrm{N} / \mathrm{A}$ : not applicable. 
Figure 1. Flow diagram of screening process and results.

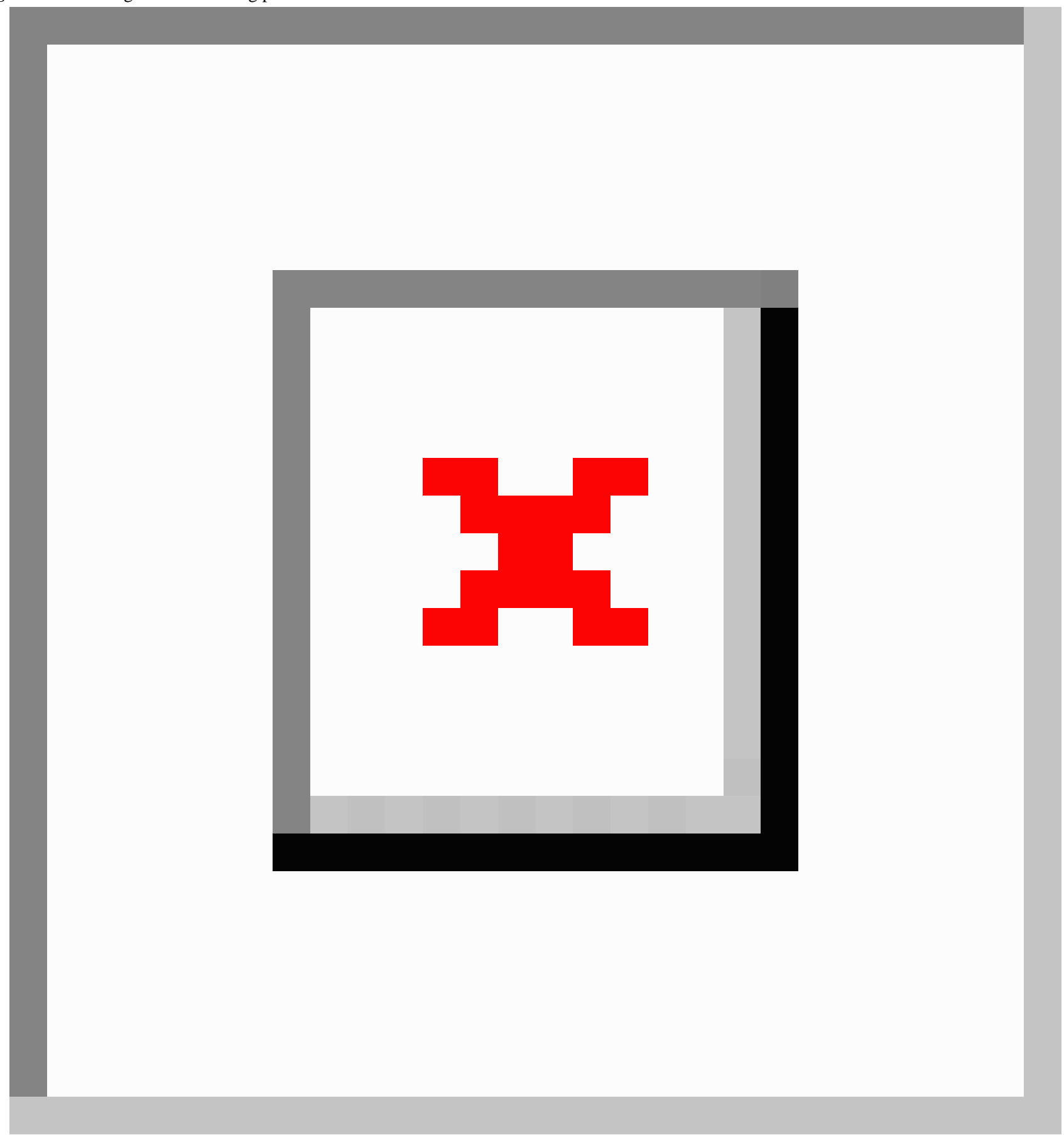


Figure 2. Wearable devices used in the included studies: (a) Fitbit One, (b) the PAM (new model shown), (c) SenseWear, (d) Actical, (e) Polar Active, and (f) Polar heart rate monitor.

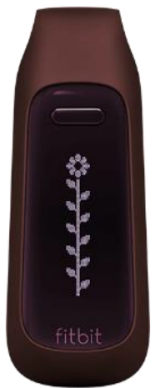

(a)

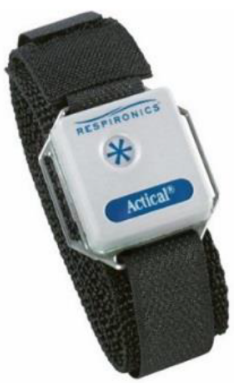

(d)

\section{Intervention Studies}

In the Netherlands, Slootmaker and colleagues [26] investigated the effectiveness of the PAM monitor in combination with PAM $\mathrm{COACH}$ for increasing the physical activity levels of adolescents (aged 13-17 years; $n=87$ ). Activity data from the PAM device were uploaded to PAM $\mathrm{COACH}$, which was a Web-based system for self-monitoring activity levels and setting goals. At the conclusion of the 3-month intervention, girls in the intervention group increased their self-reported weekly moderate physical activity relative to controls (equated to $\sim 59 \mathrm{~min} /$ day), though this was not evident at 8 months postintervention. No intervention effects were observed for boys after 3 months, though self-reported sedentary time was lower at 8 months relative to boys in the control group ( $\sim 257 \mathrm{~min} /$ day). Greater adherence to the study (eg, log-in and upload frequency to PAM $\mathrm{COACH}$ ) was not associated with greater physical activity. Minimal attrition was observed, with $78 \%$ and $91 \%$ of participants providing follow-up data at 3 and 8 months postintervention, respectively. Overall, the PAM was viewed positively by participants, and $65 \%$ reported regular wear, though monitor loss (12\%) and damage (7\%) may have influenced the results.

Hayes and Van Camp [25] used the Fitbit (model not reported) as a tool for increasing 6 grade 3 (8 years old) girls' physical activity levels during school recess. After baseline data were collected from 7 recess periods, girls were provided with step goals (increments based on baseline data) for 7 further recess periods and were encouraged to self-monitor their steps against these goals. Following this, data were then collected for a further
7 periods (no step goals provided). The project culminated in a final intervention session where 3 goals were given, and a tangible reward (eg, a small toy) was provided based on the goal(s) achieved. The number of steps taken increased by $47 \%$ from baseline (1326 steps) to intervention (1956 steps; contribution of $18 \%$ to daily step recommendations [30]), while the proportion of time spent in MVPA increased from $4 \%$ to $25 \%$, which equates to 5 minutes of MVPA during recess, or a contribution of $8 \%$ to daily recommendations [5]. Without the use of the Fitbit to self-monitor recess activity, steps taken and MVPA decreased to initial baseline levels. Basic process evaluation measures suggested that data were lost due to syncing issues, particularly during later recess sessions.

Hooke and colleagues [27] examined the efficacy of the Fitbit One to promote physical activity in clinical settings. A total of 16 children (mean age 8.7, SD 3.1 years) with acute lymphoblastic leukemia were provided with a Fitbit to wear for 17 days prior to and 5 days during a corticosteroid pulse. Monitoring over 3 days was used to identify baseline activity levels. Step goals were then tailored for each participant by a research nurse, and daily feedback was provided against these goals. No significant increases in daily steps were recorded, though there was a trend for steps to increase from week 1 to week 2 (average of 269 steps/day; $2 \%$ of daily step guidelines [30]) but to decrease from week 2 to week 3 (average of 307 steps/day). Process evaluation indicated that participants and their families were able to use the Fitbit One and the accompanying website, that they liked the Fitbit, and that data were available for $92 \%$ of measured days. 


\section{Feasibility Studies}

Schaefer and colleagues conducted 2 feasibility studies in US primary school-age children [28,29]. In the first, 24 children each wore 4 activity monitors (Actical, SenseWear, Polar Active, and Polar heart rate monitor) separately for 1 week [29]. Of these activity monitors, the Polar Active and SenseWear met the definition of a wearable activity tracker. Following each week of wear, children and their parents were interviewed about their experiences of using the monitors. Overall, the Polar Active was the most popular monitor, with its comfort and feedback features (including a clock function) noted. It was used for $98 \%$ of the total time. In comparison, the SenseWear was the least popular, largely due to its placement on the arm (uncomfortable, embarrassing). This also corresponded with its lack of use (28\% of the total time). No reactivity to wear was reported for the Polar Active.

In their second study, Schaefer and colleagues examined the feasibility of the Fitbit One in children aged 11-12 years attending a school located in an area of socioeconomic disadvantage [28]. Initially, 24 children were provided with a Fitbit to monitor their activity levels during an after-school program. After several weeks (approximately 1 month), children were provided with a Fitbit to wear every day for 5 months. On average, children accumulated 8406 steps/day. The number of steps taken increased during the monitoring phase, but not significantly. On average, 58 days of data were collected from each participant during the study, of which 19 days were considered to be valid days (overall use of $15 \%$ ). Only 2 participants were still using their Fitbit at the end of the study $(8 \%)$. Interview data indicated that, while the range of functions were well received, the design of the Fitbit One was unpopular and it was easy to forget to wear. Some children reported using the monitor to try to change behavior, while others (mainly boys) used it to compete against each other. One of the biggest barriers to use was the children's ability to sync and access their data outside of the after-school program.

\section{Discussion}

\section{Principal Findings}

This systematic, narrative review evaluated the effectiveness of wearable activity trackers as a tool for increasing children's and adolescents' physical activity levels. We also examined the feasibility of using wearable activity trackers in this population. Overall, there is a dearth of studies that have reported the use of wearable activity trackers in youth populations to increase activity levels. We identified 3 intervention studies, with 1 implemented in school-age children [25], 1 in a clinical population [27], and 1 with adolescents [26], the latter being the only study to use a randomized controlled trial design. There was some evidence to suggest that wearable activity trackers may have the potential to increase youth activity levels, with increases in physical activity compared with baseline or a control group observed. In addition, there was some evidence that wearable activity trackers were viewed positively by youth and they enjoyed wearing them. However, given that the studies had numerous methodological shortcomings and the majority of the reported differences were largely nonsignificant, it is clear that further research using rigorous and well-designed methodologies is needed to establish the effectiveness of these devices for increasing youth activity levels.

\section{Intervention Effects}

The limited intervention effects observed in studies included in this review may be attributable to several factors. First, the length of the interventions implemented ranged from 19 days to 3 months. It is possible that the shorter intervention periods were not sufficient to change behavior, a notion supported by a recent review that highlighted that behavioral interventions of longer durations ( $\geq 6$ months) had greater success in changing physical activity levels [31]. There is a clear need for studies using longer measurement periods to examine the effectiveness of these devices in youth. Second, it is not clear whether the interventions were grounded on behavioral theories, which are critical for intervention effectiveness [32]. Third, 2 of the studies may have been underpowered to detect a change in physical activity due to the smaller number of children recruited [25,27]. Fourth, intervention effects were not examined using validated objective monitors (eg, accelerometers). While several studies used data from the wearable activity tracker, these devices have not been validated for assessing physical activity outcomes in youth to date [18]. This could be viewed as a limitation of these included studies. However, this may be less of an issue if the focus of an intervention study is to use the device as a tool to facilitate behavior change rather than to evaluate the outcome (ie, validity and reliability should be established prior to such use). In the only study to report significant effects, self-reported physical activity data were collected using a questionnaire with low validity [26]. There is a clear need for longer-term studies using randomized controlled trials that are grounded on behavioral theories to identify the effectiveness of wearable activity trackers for changing youth physical activity behavior.

\section{Self-Monitoring Using Wearable Activity Trackers}

A common feature of the identified intervention studies was that the wearable activity tracker was used to self-monitor physical activity in combination with different intervention approaches [17]. Unsurprisingly, these intervention approaches largely consisted of goal setting, identified as an effective behavior change technique [11] to enhance physical activity levels [33]. However, there was some variability in who set the goals. In the interventions with children, the researchers set the goals based on baseline values obtained, and then provided regular support [27] or rewards [25] in relation to reaching the goals. In contrast, the adolescents had an opportunity to set their own activity goal and then received tailored advice to achieve these based on their preferred activities [26]. While research has shown that assigned goals are as effective as self-set goals, provided the reason for the goal is given [34], it is unclear whether the included studies provided this information to participants. It is important for future research to establish how youth engage with wearable activity trackers (eg, is the frequency of self-monitoring mediated by the activity goal source?), as this will provide critical insights into how these devices can be integrated into future interventions and strategies for engaging children and adolescents in the behavior change process. 


\section{Sustainability of Wearable Activity Trackers Over Time}

Arguably, one of the biggest concerns regarding wearable activity trackers is whether individuals sustain their engagement with the technology over time [16]. Research has suggested that approximately one-third of US adults stop using their wearable activity tracker after 6 months [16], with expectation mismatch (ie, the technology doesn't do what was expected) a commonly cited reason [35]. While it is difficult to draw any conclusions about this due to the small number of studies identified and the variability in the length of time the wearable activity trackers were worn, there is some preliminary evidence to suggest that youth might regularly use the technology to self-monitor their physical activity levels when the technology is integrated into an intervention [26,27], but sustained use may not be observed in the longer term when these devices are simply provided to youth to use [28]. Interestingly, Slootmaker and colleagues found that the frequency that adolescents uploaded their data to PAM COACH was not associated with physical activity, yet physical activity levels were found to increase in girls at 3 months and sedentary time decreased in boys at 8 months [26]. These results could be explained by the lower activity levels of the girls in the study compared with boys; therefore, girls could achieve greater gains in activity levels [26]. However, it is also possible that there are different degrees of engagement, ranging from brief glances at the device [36], to tracking activity across the day using the monitor, to using specific functions within the accompanying app (eg, trends data), which may mediate the efficacy of the device on activity levels. Research is needed to provide further evidence about how youth engage with these devices and the accompanying apps over time (eg, attrition rates), whether this differs by population subgroups (eg, sex, age), whether the engagement with different features may have differential effects, and reasons for potential changes in use over time. Such research will be critical for identifying how to incorporate wearable activity trackers into interventions, and for informing best practice in future physical activity interventions and health promotion practice.

\section{Feasibility of Wearable Activity Trackers in Youth}

This review identified few studies that have examined the feasibility of using wearable activity trackers in children and adolescents, either as part of an intervention or as a stand-alone study. While these technologies offer significant promise for increasing physical activity levels and benefiting health promotion practice [14] or, potentially, clinically relevant outcomes in healthy and clinical populations [27], it is important to establish whether wearable activity trackers are a practical tool for youth to use regardless of the setting. Overall, the results from this review suggest that such devices were viewed positively by youth and their parents [26-29], and that they appreciated the devices' range of functions, which included the tracking of physical activity. Ease of use, comfort, and aesthetics were important to the participants [28,29], which is an interesting point to note given that such devices are unlikely to have been developed with youth in mind [35]. Such factors have been previously identified as important and potential barriers to use in adults $[37,38]$. Interestingly, while there was some evidence that youth used their wearable activity tracker to compete with (boys) or support (girls) each other [28], which has also been observed in adults [37], few studies noted concerns over the accuracy of the devices. Schaefer and colleagues found that, while some children did test the accuracy of the monitors [28], this did not appear to influence use. Of potentially greater concern, access to technology was identified as a potential issue in low-socioeconomic-status youth, such as the ability to sync and access data at home [28]. This supports a previous study that found that the use of a mobile phone app that enabled boys from low-socioeconomic areas to track their goals and behavior was moderate, due to their prioritizing data for entertainment over the app [39]. As such, we recommend that researchers examine the feasibility and acceptability of different devices, and we suggest that youth are interested in using wearable activity trackers and that these devices are feasible for use in both clinical and healthy populations. However, it must be noted that there are issues concerning the age required ( $\geq 13$ years old) to hold an account associated with wearable activity trackers that may preclude their use with children, unless alternative feedback mechanisms are employed (eg, researcher-led feedback $[25,27])$. Identifying how best to integrate the functions and features of wearable activity trackers into physical activity interventions, in order to maximize their potential within the population of interest, should be a future area of research.

\section{Limitations}

There are some limitations in this review that warrant attention. First, this review highlights the surprisingly small number of studies that have used wearable activity trackers in youth despite their widespread prevalence in daily life. This makes it difficult to establish any firm conclusions. Given the pervasiveness of these technologies and widespread appeal, further research is needed to explore these issues in youth in order to inform interventions and public health guidance. In addition, research is needed to establish whether differential effects are observed based on the age of the participants. Second, the quality of the included studies was low, with only 1 study using a randomized controlled design and evaluating intervention effects over a 3 -month period. There is a need for more rigorous and robust intervention designs to evaluate the longer-term effectiveness of these devices on youth physical activity levels. Third, while a range of monitors were used in the included studies, some monitors have since been discontinued (eg, PAM, SenseWear) or largely usurped by new models (eg, Fitbit). In addition, the validity and reliability of these devices in youth has not been established.

\section{Conclusions}

There is a paucity of literature concerning the effectiveness of wearable activity trackers as a tool for increasing children's and adolescents' physical activity levels. Additionally, little research has documented the feasibility of such technology in youth. While there are some preliminary data to suggest that wearable activity trackers are feasible and may have the potential to increase physical activity levels through self-monitoring and goal setting in youth, there is a clear need for more research to examine these issues in youth using robust studies with longer measurement periods. Given the constant changes in the wearable technology market (eg, newer devices and models are 
regularly available), research should primarily focus on the use of the device as a tool for changing behavior in youth in interventions. Focusing on features common to different wearable device brands (eg, self-monitoring displays, accompanying apps, and biofeedback features) may be important for establishing the feasibility of these technologies in youth rather than that of the individual monitors per se. Based on this review, feasibility research should establish how youth engage with this technology, whether adherence and engagement are sustained or change over time, and whether effects vary based on age and sex. Such information will inform the development of future interventions and identify how to maximize the potential contribution that such pervasive technologies could make to physical activity promotion in youth.

\section{Conflicts of Interest}

None declared.

\section{Multimedia Appendix 1}

Search strategy for each database.

[PDF File (Adobe PDF File), 23KB-Multimedia Appendix 1]

\section{References}

1. Kohl HW, Craig CL, Lambert EV, Inoue S, Alkandari JR, Leetongin G, Lancet Physical Activity Series Working Group. The pandemic of physical inactivity: global action for public health. Lancet 2012 Jul 21;380(9838):294-305. [doi: 10.1016/S0140-6736(12)60898-8] [Medline: 22818941]

2. Andersen LB, Harro M, Sardinha LB, Froberg K, Ekelund U, Brage S, et al. Physical activity and clustered cardiovascular risk in children: a cross-sectional study (The European Youth Heart Study). Lancet 2006 Jul 22;368(9532):299-304. [doi: 10.1016/S0140-6736(06)69075-2] [Medline: 16860699]

3. Janssen I, Leblanc AG. Systematic review of the health benefits of physical activity and fitness in school-aged children and youth. Int J Behav Nutr Phys Act 2010;7:40 [FREE Full text] [doi: 10.1186/1479-5868-7-40] [Medline: 20459784]

4. Hallal PC, Victora CG, Azevedo MR, Wells JCK. Adolescent physical activity and health: a systematic review. Sports Med 2006;36(12):1019-1030. [Medline: 17123326]

5. Department of Health. Does your child get 60 minutes of physical activity every day? Make your move - Sit less! Be active for life! Australia's Physical Activity \& Sedentary Behaviour Guidelines for Children (5-12 years). 2014. URL: http://www. health.gov.au/internet/main/publishing.nsf/content/health-pubhlth-strateg-phys-act-guidelines [accessed 2016-11-17] [WebCite Cache ID 6m693PR10]

6. U.S. Department of Health \& Human Services. Physical activity guidelines for Americans. 2008. URL: https://health.gov/ paguidelines/ [accessed 2016-11-18] [WebCite Cache ID 6m69Tq6UI]

7. Chief Medical Officer. UK physical activity guidelines: children and young people. Department of Health. 2011. URL: https://www.gov.uk/government/publications/uk-physical-activity-guidelines [accessed 2016-08-16] [WebCite Cache ID 6L0w51LY5]

8. Schranz N, Olds T, Cliff D, Davern M, Engelen L, Giles-Corti B, et al. Results from Australia's 2014 Report Card on Physical Activity for Children and Youth. J Phys Act Health 2014 May;11 Suppl 1:S21-S25. [doi: 10.1123/jpah.2014-0164] [Medline: 25426909]

9. Dentro KN, Beals K, Crouter SE, Eisenmann JC, McKenzie TL, Pate RR, et al. Results from the United States' 2014 Report Card on Physical Activity for Children and Youth. J Phys Act Health 2014 May;11 Suppl 1:S105-S112. [doi: 10.1123/jpah.2014-0184] [Medline: 25426905]

10. Standage M, Wilkie HJ, Jago R, Foster C, Goad MA, Cumming SP. Results from England's 2014 Report Card on Physical Activity for Children and Youth. J Phys Act Health 2014 May;11 Suppl 1:S45-S50. [doi: 10.1123/jpah.2014-0165] [Medline: 25426913]

11. Michie S, Richardson M, Johnston M, Abraham C, Francis J, Hardeman W, et al. The behavior change technique taxonomy (v1) of 93 hierarchically clustered techniques: building an international consensus for the reporting of behavior change interventions. Ann Behav Med 2013 Aug;46(1):81-95. [doi: 10.1007/s12160-013-9486-6] [Medline: 23512568]

12. Corder K, van Sluijs EMF, Goodyer I, Ridgway CL, Steele RM, Bamber D, et al. Physical activity awareness of British adolescents. Arch Pediatr Adolesc Med 2011 Jul;165(7):603-609. [doi: 10.1001/archpediatrics.2011.94] [Medline: 21727272]

13. Lubans DR, Plotnikoff RC, Miller A, Scott JJ, Thompson D, Tudor-Locke C. Using pedometers for measuring and increasing physical activity in children and adolescents: the next step. Am J Lifestyle Med 2014 Jul 10;9(6):418-427. [doi: $10.1177 / 1559827614537774]$

14. Fritz T, Huang E, Murphy G, Zimmerman T. Persuasive technology in the real world: a study of long-term use of activity sensing devices for fitness. Presented at: CHI Conference on Human Factors in Computing Systems; April 26-May 1, 2014; Toronto, ON, Canada. [doi: 10.1145/2556288.2557383]

15. Pureprofile. Wearables work - Australians more active with fitness trackers. 2015. URL: http://businesses.pureprofile.com/ news/wearables-work-australians-more-active-with-fitness-trackers [accessed 2016-11-18] [WebCite Cache ID 6m6AFkxZf] 
16. Ledger D, McCaffrey D. Jan. Inside wearables: how the science of human behavior change offers the secret to long-term engagement. Endeavour Partners LLC. 2014 Jan. URL: http://endeavourpartners.net/assets/

Wearables-and-the-Science-of-Human-Behavior-Change-EP4.pdf [accessed 2016-11-18] [WebCite Cache ID 6m74dmoVY]

17. Lyons EJ, Lewis ZH, Mayrsohn BG, Rowland JL. Behavior change techniques implemented in electronic lifestyle activity monitors: a systematic content analysis. J Med Internet Res 2014;16(8):e192 [FREE Full text] [doi: 10.2196/jmir.3469] [Medline: 25131661]

18. Evenson KR, Goto MM, Furberg RD. Systematic review of the validity and reliability of consumer-wearable activity trackers. Int J Behav Nutr Phys Act 2015;12(1):159 [FREE Full text] [doi: 10.1186/s12966-015-0314-1] [Medline: 26684758]

19. Lewis ZH, Lyons EJ, Jarvis JM, Baillargeon J. Using an electronic activity monitor system as an intervention modality: a systematic review. BMC Public Health 2015;15:585 [FREE Full text] [doi: 10.1186/s12889-015-1947-3] [Medline: 26104189]

20. Salmon J. Novel strategies to promote children's physical activities and reduce sedentary behavior. J Phys Act Health 2010 Nov;7 Suppl 3:S299-S306. [Medline: 21116014]

21. Moher D, Liberati A, Tetzlaff J, Altman DG. Preferred reporting items for systematic reviews and meta-analyses: the PRISMA Statement. Open Med 2009;3(3):e123-e130 [FREE Full text] [Medline: 21603045]

22. Horsley T, Dingwall O, Sampson M. Checking reference lists to find additional studies for systematic reviews. Cochrane Database Syst Rev 2011 Aug 10(8):MR000026. [doi: 10.1002/14651858.MR000026.pub2] [Medline: 21833989]

23. Hoy MB. Personal activity trackers and the quantified self. Med Ref Serv Q 2016;35(1):94-100. [doi: 10.1080/02763869.2016.1117300] [Medline: 26794199]

24. Viswanathan M, Ansari M, Berkman N, Chang S, Hartling L, McPheeters L, et al. Assessing the risk of bias of individual studies in systematic reviews of health care interventions. Agency for Healthcare Research and Quality Methods Guide for Comparative Effectiveness Reviews 2012 Mar 08 [FREE Full text] [Medline: 22479713]

25. Hayes LB, Van Camp CM. Increasing physical activity of children during school recess. J Appl Behav Anal 2015 Sep;48(3):690-695. [doi: 10.1002/jaba.222] [Medline: 26119136]

26. Slootmaker SM, Chinapaw MJM, Seidell JC, van Mechelen W, Schuit AJ. Accelerometers and Internet for physical activity promotion in youth? Feasibility and effectiveness of a minimal intervention [ISRCTN93896459]. Prev Med 2010 Jul;51(1):31-36. [doi: 10.1016/j.ypmed.2010.03.015] [Medline: 20380847]

27. Hooke MC, Gilchrist L, Tanner L, Hart N, Withycombe JS. Use of a fitness tracker to promote physical activity in children with acute lymphoblastic leukemia. Pediatr Blood Cancer 2016 Apr;63(4):684-689. [doi: 10.1002/pbc.25860] [Medline: 26756736]

28. Schaefer SE, Ching CC, Breen H, German JB. Wearing, thinking, and moving: testing the feasibility of fitness tracking with urban youth. Am J Health Educ 2016 Jan 08;47(1):8-16. [doi: 10.1080/19325037.2015.1111174]

29. Schaefer SE, Van Loan M, German JB. A feasibility study of wearable activity monitors for pre-adolescent school-age children. Prev Chronic Dis 2014;11:E85 [FREE Full text] [doi: 10.5888/pcd11.130262] [Medline: 24854236]

30. Tudor-Locke C, Craig CL, Beets MW, Belton S, Cardon GM, Duncan S, et al. How many steps/day are enough? for children and adolescents. Int J Behav Nutr Phys Act 2011;8:78 [FREE Full text] [doi: 10.1186/1479-5868-8-78] [Medline: 21798014]

31. Nguyen S, Häcker A, Henderson M, Barnett T, Mathieu M, Pagani L, et al. Physical activity programs with post-intervention follow-up in children: a comprehensive review according to categories of intervention. Int J Environ Res Public Health 2016;13(7) [FREE Full text] [doi: 10.3390/ijerph13070664] [Medline: 27376315]

32. Salmon J, Booth ML, Phongsavan P, Murphy N, Timperio A. Promoting physical activity participation among children and adolescents. Epidemiol Rev 2007;29:144-159. [doi: 10.1093/epirev/mxm010] [Medline: 17556765]

33. Williams SL, French DP. What are the most effective intervention techniques for changing physical activity self-efficacy and physical activity behaviour-and are they the same? Health Educ Res 2011 Apr;26(2):308-322 [FREE Full text] [doi: 10.1093/her/cyr005] [Medline: 21321008]

34. Locke EA, Latham GP. Building a practically useful theory of goal setting and task motivation: a 35-year odyssey. Am Psychol 2002 Sep;57(9):705-717. [Medline: 12237980]

35. Clawson J, Pater J, Miller A, Mynatt E, Mamykina L. No longer wearing: investigating the abandonment of personal health-tracking technologies on Craigslist. Presented at: UbComp'15; September 7-11, 2015; Osaka, Japan. [doi: $10.1145 / 2750858.2807554]$

36. Gouveia R, Karapanos E, Hassenzahl M. How do we engage with activity trackers? A longitudinal study of study of Habito. Presented at: UbComp'15; September 7-11, 2015; Osaka, Japan.

37. Harrison D, Marshall P, Bianchi-Berthouze N, Bird J. Activity tracking: garriers, workarounds and customisation. Presented at: UbComp'15; September 7-11, 2015; Osaka, Japan p. 617-621.

38. Ledger D. Inside Wearables - Part 2: A Look at the Uncertain Future of Smart Wearable Devices, and Five Industry Developments That Will Be Necessary for Meaningful Mass Market Adoption and Sustained Engagement. Cambridge, MA: Endeavour Partners LLC; 2014.

39. Smith JJ, Morgan PJ, Plotnikoff RC, Dally KA, Salmon J, Okely AD, et al. Smart-phone obesity prevention trial for adolescent boys in low-income communities: the ATLAS RCT. Pediatrics 2014 Sep;134(3):e723-e731 [FREE Full text] [doi: 10.1542/peds.2014-1012] [Medline: 25157000] 


\section{Abbreviations}

MVPA: moderate- to vigorous-intensity physical activity

PRISMA: Preferred Reporting Items for Systematic Reviews and Meta-Analyses

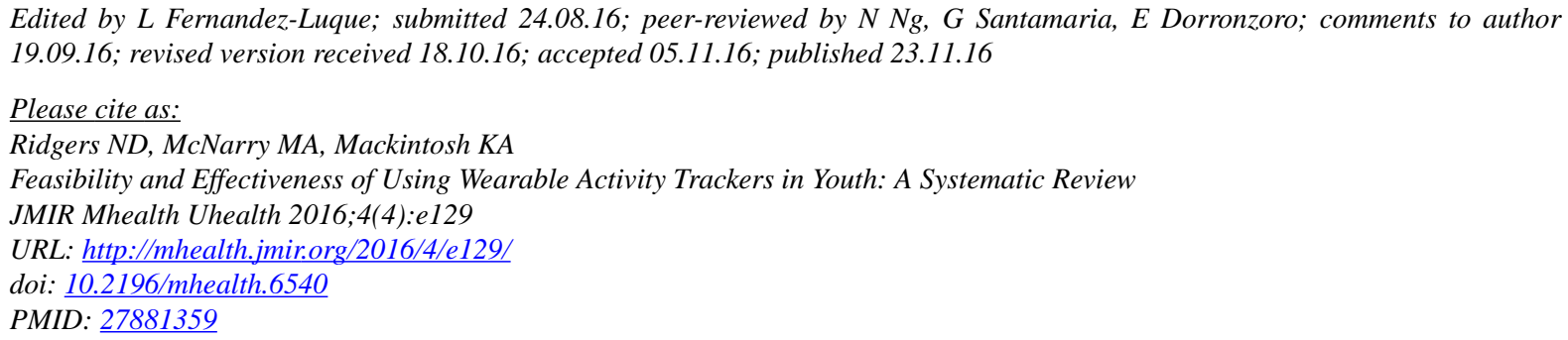

CNicola D Ridgers, Melitta A McNarry, Kelly A Mackintosh. Originally published in JMIR Mhealth and Uhealth (http://mhealth.jmir.org), 23.11.2016. This is an open-access article distributed under the terms of the Creative Commons Attribution License (http://creativecommons.org/licenses/by/2.0/), which permits unrestricted use, distribution, and reproduction in any medium, provided the original work, first published in JMIR mhealth and uhealth, is properly cited. The complete bibliographic information, a link to the original publication on http://mhealth.jmir.org/, as well as this copyright and license information must be included. 